\section{Galileo and Scientific History}

A LETTER has been received from Prof. Lane Cooper with reference to the article by Prof. A. S. Eve which appeared in NATURE of January 4 (p. 8). Prof. Lane Cooper suggests that physicists should find much to interest them in Aristotle's "Dynamies" (pp. 26-33) and in Aristotle's "Physies", edited by W. D. Ross (Oxford, 1936). There is a further suggestion that Salviati may have referred to the Tower of Pisa (178 ft.), while Sagredi might have considered the Campanile of Venice (323 ft.). Prof. Lane Cooper directs attention to the curious mistake of Galileo, namely, that "in free fall, wood starts off faster than lead". Moreover, Galileo, about 1590, claims that he had "often tested this". It must be remembered that Prof. Lane Cooper's main interest is in language and literature, and that his personal interest lay in the growth of a myth. $\mathrm{He}$ further questions whether those who suppose that a theatrical Galileo ascended the Tower, after due advertisement, to perform modern experiments with free fall before the mob, are really honouring that great and good man. "If Stokes and Rayleigh had lived in Galileo's day, would either of them have lent himself to a display of the sort ?"

\section{Control of Power Networks}

THE problem of nation-wide electricity supply has undergone considerable changes in recent years. Electric power has been applied to many services, with the result that continuity of supply has now become almost essential to the life of the community. Economy in capital costs entails the reduction of spare plant to a minimum by creating a common pool. Economy in running costs necessitates the placing of the generating stations in such positions that fuel and water costs are reduced to a minimum. This has led to the linking up of distributing networks and power stations, and it is essential that the controlling engineer should be immediately informed of any appreciable change in the load on the networks. This subject was discussed in a paper read to the Institution of Electrical Engineers on February 7 by G. A. Burns and T. R. Rayner. They describe the automatic methods by means of which the engineer is at once informed of the state of the load at a distribution substation, and the methods by means of which the apparatus is started and circuits opened and closed without using any manual labour. There are already in service on various sections of the British grid 150 installations of the apparatus the authors described. It embodies automatic telephone apparatus spread over very wide areas. The components employed are the same as those incorporated in about eleven million lines of automatic telephones spread over practically every country in the world. This proves the robustness of construction and the stability of the apparatus components used in the system described in the paper. It is interesting to notice that the problems arising in connexion with the control, distribution and protection of power networks have been practically solved by the adaptation of methods and apparatus used in automatic telephony.

\section{Mathematics in Engineering}

THF scholastic method of dividing mathematics into various branches called geometry, algebra, trigonometry, calculus, etc., has advantages from the point of view of the teacher, but according to Dr. A. Russell, in the Faraday House Journal for the Lent term 1936, there is no need for the engineering student to handicap himself by solving a problem by some particular method. This custom was fostered in Great Britain some fifty years ago by the old. fashioned syllabus for the Cambridge Mathematical Tripos. In the old days, the Tripos used to last for nine days, and was divided into two periods of four and five days each, separated by an interval of ten days. Four of the papers were marked in the syllabus 'easy problems'; but few of them were easy. The problem papers sometimes had between twenty and thirty questions, and so the time of most of the candidates was largely expended on reading them. The candidates were also harassed by hearing quill pens scratching and squeaking all round them, as fountain pens were not then used. During the first three days of the examination, the use of the calculus was taboo. In the Euclid paper, the use of algebra or trigonometry was not permitted. In another paper the candidates were examined on the first three sections of Newton's "Principia". This was not difficult, but the riders were, as it was imperative to prove them by Newton's methods. These were the days in which there was a 'senior wrangler', and the mathematical coaches coveted the honour of having trained one almost as much as the owner of a racing colt covets winning the Derby. Dr. Russell illustrates the 'all-in' methods by applying them to geometrical problems.

\section{Bathymetry of the Oceans}

THE nomenclature of ocean deeps is still in some confusion, and this is largely due to the use of fathoms in Great Britain and metres in most other countries in the record of depths. In the Challenger reports, Sir John Murray named the areas over 3,000 fathoms as 'deeps'. This figure was arbitrary and when con. verted into metres (5,486 metres) has even less significance as a criterion of depth, although the Prince of Monaco in his "Carte générale bathy. métrique" of 1912 adopted the near equivalent of 6,000 metres and many of the Challenger names. In Petermann's Mitteilungen of February, Dr. G. Wüst proposes a new system of nomenclature for the ocean features of the world which incorporates a good deal already in use by G. Schott. He chooses 4,000 metres $(2,187$ fathoms) as his standard. In depths of less the bottom figures as ridges : in depths of more as basins. The 'deeps' in the older sense of the term disappear from Dr. Wüst's map. Each feature receives a geographical name derived from its location, and the personal names commemorating oceanographers are not used. The figure of 4,000 metres is of course arbitrary except in so far as it approximates to the depths at which the average ocean floor lies. The map shows both Atlantic and Indian Oceans divided into east and west troughs, 